\title{
A radiology survey and sub-sub-specialization in hematopathology
}

\author{
William R. Macon ${ }^{1}$
}

Published online: 11 February 2021

(C) The Author(s), under exclusive licence to Springer-Verlag GmbH, DE part of Springer Nature 2021

I occasionally peruse on-line publications from non-pathology fields of medicine, such as Radiology Business (https://www. radiologybusiness.com), to see what issues confronting other medical specialties may be current or future topics of interest to pathologists and hematopathologists. For instance, subspecialization has been and continues to be a subject of debate, sometimes heated, within medical specialties over the past 25 plus years.

A recent 124-question on-line survey of full members of the European Society of Radiology (ESR) received responses from 1344 radiologists from 49 countries [1]. Slightly more than one-half of those responding ESR radiologists practiced in academic institutions and nearly one-quarter each worked in non-university teaching hospitals or in non-teaching district general/community hospitals or private practice [1]. One of the four main themes of the survey was "about you, your training, and your clinical role," which included some questions regarding sub-specialization [1].

Of 1291 respondents, $92 \%$ agreed that having an area of sub-specialization was important, whereas less than $10 \%$ thought that general work is most in demand [1]. As might be predicted, written comments on this topic included "many reflecting the tension between the need to cover the general clinical service against the need to offer a sub-specialist expert opinion, to contribute to excellence in patient care in highly complex imaging scenarios" [1]. It is interesting to note that sub-specialty accreditation was felt to improve an individual's identity as a radiologist to self and to clinical colleagues among approximately $85 \%$ of 1291 of the respondents [1]. However, only $47 \%$ of 1302 respondents had completed sub-specialty training/clinical fellowships [1].

No such surveys of pathologists and hematopathologists could be found upon searching PubMed Central@ (https://www.ncbi. nlm.nih.gov/pmc) and Google Scholar (https://scholar.google. com). Most papers dealing with sub-specialization in anatomic/

William R. Macon

macon.william@mayo.edu

1 Mayo Clinic, Rochester, MN, USA surgical pathology have been on the transition from a general practice to a sub-specialty practice at local institutions $[2,3]$ or on diagnostic quality assessment between sub-specialized and general pathology practices and practitioners [4-6].

The main reason cited by Sarewitz for evolving to subspecialty models of practice from a general form of practice in anatomic and clinical pathology [7] also exists in the hematopathology sub-specialty, that of "unabated information explosion". Functional sub-sub-specialization in hematopathology has already developed at some large institutions with broad, high volume practices such as at MD Anderson Cancer Center in Houston, TX, USA, where the Department of Hematopathology has Sections of Bone Marrow, Lymphoma Pathology, Molecular Diagnostics, Clinical Flow Cytometry, Cytogenetics, and Outside Services (https://www.mdanderson.org/research/departments-labsinstitutes/departments-divisions/hematopathology/sections.html) , and at Mayo Clinic in Rochester, MN, USA, where the Division of Hematopathology has separate Bone Marrow and Lymphoma Working Groups and Hematopathology laboratory practices in Cell Kinetics (i.e., flow cytometry), Metabolic Hematology (i.e., red blood cell disorders), Molecular Hematopathology, Hematopathology Morphology (i.e., abnormal peripheral blood smears), Special Coagulation, and Special DNA Coagulation (https://www.mayoclinic.org/departments-centers/laboratorymedicine-pathology/overview/specialty-groups/ hematopathology).

While it would be interesting to have a broad survey of pathologists that includes queries about sub-specialty versus general practice like that performed by the ESR, it would be provocative to survey hematopathologists "about you, your training, and your clinical role" in the context of sub-subspecialization in their field.

\section{References}

1. European Society of Radiology (ESR) (2020) The identity and role of the radiologist in 2020: a survey among ESR full radiologist members. Insights Imaging Dec 11:130 
2. Black-Schaffer WS, Young RH, Harris NL (1996) Subspecialization of surgical pathology at the Massachusetts General Hospital. Am J Clin Pathol 106(4 Suppl 1):S33-S42

3. Groppi DE, Alexis CE, Sugrue CF, Bevis CC, Bhuiya TA, Crawford JM (2013) Consolidation of the North Shore-LIJ Health System anatomic pathology services: the challenge of subspecialization, operations, quality management, staffing, and education. Am J Clin Pathol 140:20-30

4. Liu Y-J, Kessler M, Zander DS, Karamchandani DM (2016) Trends in extramural consultation: comparison between subspecialized and general surgical pathology service models. Ann Diagn Pathol 20:2024
5. Jakate K, De Brot M, Goldberg F, Muradali D, O'Malley FP, Mulligan AM (2012) Papillary lesions of the breast: impact of breast pathology subspecialization on core biopsy and excision diagnoses. Am J Surg Pathol 36:544-551

6. Sinno SAJ, Chakhachiro ZI, Nassif SR (2018) Review of hematopathology consult cases: a two-year experience in a tertiary referral center in Lebanon. Biomed Res Int 2018:3028625

7. Sarewitz SJ (2014) Subspecialization in community pathology practice. Arch Pathol Lab Med 138:871-872

Publisher's note Springer Nature remains neutral with regard to jurisdictional claims in published maps and institutional affiliations. 